\title{
Interface of an Old Version of Raman Spectrophotometer (Ramanor HG.2S JOBIN YVON) by LabVIEW
}

\author{
doi:10.3991/ijoe.v6i2.1141 \\ A.I.Adam ${ }^{1}$, S.T.Kafi ${ }^{2}$ \\ ${ }^{1}$ Central Laboratory Ministry of Sciences and Technology, Khartoum, Sudan \\ ${ }^{2}$ Alneelian University, Khartoum, Sudan
}

\begin{abstract}
In this work, the Raman spectrophotometer (HG.2S Jobin Yvon) was interfaced with labVIEW card to act as data acquisition system instead of the chart recorder. The interface of the Raman (HG.2S Jobin Yvon) with the labVIEW card required some modifications to the setup ,the main parts of the original setup of the systems were included an air-cooled photomultiplier tube type (RCA IP28), log amplifier, handscanning and labVIEW card, all these components were assembled and the whole setup was tested successfully .the results obtained by new device showed perfect consistency with data from literature when checked by known standard solutions .
\end{abstract}

Index terms-labVIEW, Raman, Spectrophotometer, spectroscopy

\section{INTRODUCTION}

Raman spectroscopy is a powerful analytical tool in the quantitative analysis of complex mixtures, for locating various functional groups, or chemical bond in molecules and for the elucidation of a molecular structure [5].

The invention and scientific development of Raman techniques, passed through different steps. During this progressive development it faces many problems. due to the nature of it is weak signal, strong physical and mathematical

Methods were used to overcome all these problems, to build this powerful analytical instrument.

The predication of the molecular light scattering is starting at 1922 by Smekal, Kramer's and Heisenberg, Carbons and Dirac by studying the physics and mathematical models of scattered light.

In 1928 (C.V) Raman recorded Raman spectra, by using filter sunlight, prism spectroscope and he depended on his visual observation to detect weak signal by photographic plate. In the $1930 \mathrm{C}$.V Raman awarded Nobel Prize by address that "the character of the scattered radiations enables us to obtain an insight into the ultimate structure of the scattering substance [1].

In the sixteenth of the last century Tweenes suggested laser as light source for Raman Spectroscopy as analytical tool, by using the photomultiplier tube (PMT) detector IP 28 type [1].

Major scientific development of the Raman spectrophotometer, done during the time between the 1990 to 2000. In this time period Fourier transform
-Raman was demonstrated by chase and Robitt .Bench top system was developed by Diolor and the laser diode sources and intensified charge to couple device(ICCD) are used [7] .In the beginning of the 21st century UV Raman microscope found the way to the many scientific and research applications as sophisticated instrument tool[1].

The Raman spectrophotometer is an instruments that measure the wave number from some components. It consists of four parts, namely: intense source, a sample illumination system, spectrometer and detection system . It also contains an optics and electronics components, which has been used to acquire the signals in order to be displayed in a different output format [5].

To interface Raman instrument to computer this need to establish a connection between an instrument and computer through an electronic card. labVIEW It is abbreviation of the laboratory Virtual Instrument Engineering workbench, labVIEW is a graphical programming language that uses icons, in stead of lines of text based on the programming language, where instruction determine program executions. labVIEW use dataflow programming where data determine execution [4].

There were many problems that encouraged the interfacing and rebuild of the instrument. The production of this type stopped since 1993 which means that there are no spare parts for this version of the instrument. In addition the cost of a new setup is very high and this technique is not available in the Sudanese laboratories. The missing parts included Ominiscribe chart recorder cooling system for the photomultiplier detector, hand scanning device, sample illumination system, cell holder and cuvette Handscanning faulty some devices missed, no light sources obtained and available, system not calibrated.

For the reason that the PMT detector is very sensitive to temperature, and due to the lack of cooling system in the lab, the EMI PMT detector was changed by the detector of RCA IP28 type, which is less sensitive to the temperature.

Due to the above stated problems the Raman system of the type JOBIN YVON which was available incomplete in the laser lab at the Faculty of Science and Technology, AL-Neelian University Sudan, had to be maintained and rebuilt.

\section{METHODS}

There are many steps performed in order to prepare the step for interface with a personal computer such as 
the alignment of the optical system, change of the photomultiplier, and selection of a suitable amplifier voltage output to be connected to the LabVIEW card.

\section{A. Hardware modifications}

\section{1) Alignment of the optical system}

The alignment of the optical system in this work was done manually using a He-Ne laser source. The optical path passed through the mirrors, gratings, exit slit and then to the photomultiplier tube (PMT). This was done to adjust the optical axis of the spectrophotometer.

For the light detection, (PMT) Type RCA-IP28 used instead of the EMI cooling (PMT), RCA-IP28 (PMT) is one of the most important single elements photo detectors, working in transmission mode, window material is glass UV, spectral range (185650)nm [2].

The RCA-IP28 PMT was used for many reasons: first it does not need a cooling system, Second the RCA IP28 S-5 window range of UV is very suitable for the Raman spectroscopy. Moreover this PMT type has high quantum efficiency and low dark current and noise, which is a favorable characteristic in use.

Signals from the PMT were checked by a signal generator (function mode) to ensure that the output from the photomultiplier tube reached the detector. The power supply used contained different output voltages. Oscilloscope (407 model, $\mathrm{t}=125 \mu \mathrm{s}$ ) was used to check the output from the photomultiplier tube. In order to determine suitable range for the PMT tube, linearity between the input and output voltages was traced until it reached the saturation point.

The original amplifier with the output voltage between $(18-20)$ volt, was replaced by another amplifier of the type (FACS logarithmic amplifier), because the output voltage of the log amplifier is matches our card.

Code Width is the smallest change in the signal your system can detect (determined by resolution, range, and gain)

Smaller Code Width $=$ more precise representation of your signal

Code width $=$ range $/$ gain $* 2^{\text {resoultion }}$

Suppose the gain of amplifier is 1

Table 1 and 2 describes the output voltages from amplifier four channels and two channels.

The smaller code width means more accurate measurement for this the dual amplifier four channels (Channel 3input-channel 2 output) was selected to be input for the labVIEW card.

TABLE I.

OUTPUT VOLTAGE OF FOUR CHANNELS AMPLIFIER

\begin{tabular}{|c|c|c|}
\hline $\begin{array}{c}\text { Input voltage } \\
\text { (V) }\end{array}$ & $\begin{array}{c}\text { Output } \\
\text { voltage(V) }\end{array}$ & $\begin{array}{c}\text { Code } \\
\text { width(mV) }\end{array}$ \\
\hline 18 & 18 & 4.39 \\
\hline 18 & 1.58 & 0.38 \\
\hline 18 & 1.35 & 0.32 \\
\hline 18 & 1.50 & 0.36 \\
\hline
\end{tabular}

TABLE II. THE OUTPUT VOLTAGE FOR DUAL CHANNEL AMPLIFIER

\begin{tabular}{|c|c|c|}
\hline $\begin{array}{c}\text { Input } \backslash \\
\text { voltage(V) }\end{array}$ & $\begin{array}{c}\text { Output } \\
\text { voltage(V) }\end{array}$ & $\begin{array}{c}\text { Code } \\
\text { width (mV) }\end{array}$ \\
\hline 18 & 8,86 & 2.177 \\
\hline 18 & 4,39 & 1.071 \\
\hline
\end{tabular}

\section{B. Software program for Raman spectrophotometer}

In labVIEW a user interface was built using a set of tools and objects. The user interface is known as the front panel, and the code is added using graphical representation of functions to control the front panel (see the block diagram). A 32-bit compiled applications was built, that gives the fast execution speed, needed for custom data acquisition, test, measurement and control solution [3].

\section{Front panel}

The front panel is the user interface of the virtual instrument. It was built with controls and indicators, which are the interactive input and output terminal of the V-I respectively push button, dials and other input devices, indicators and graph control simulate instrument input device, and supply data to the block diagram.

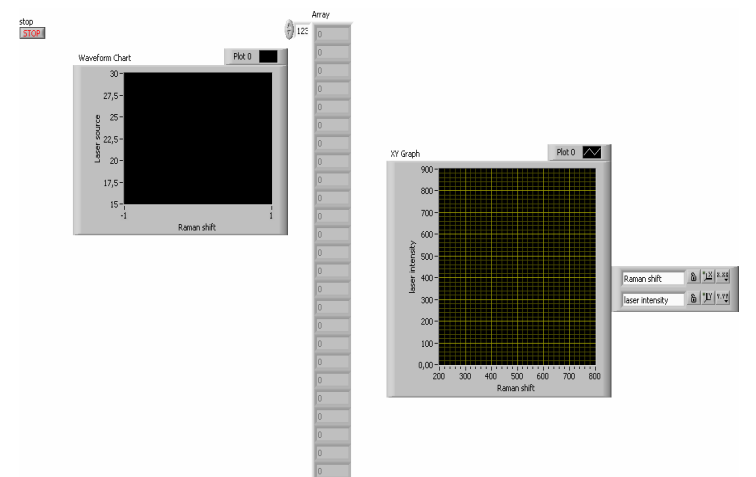

Figure 1. front panel of labVIEW program for Raman spectrophotometer.

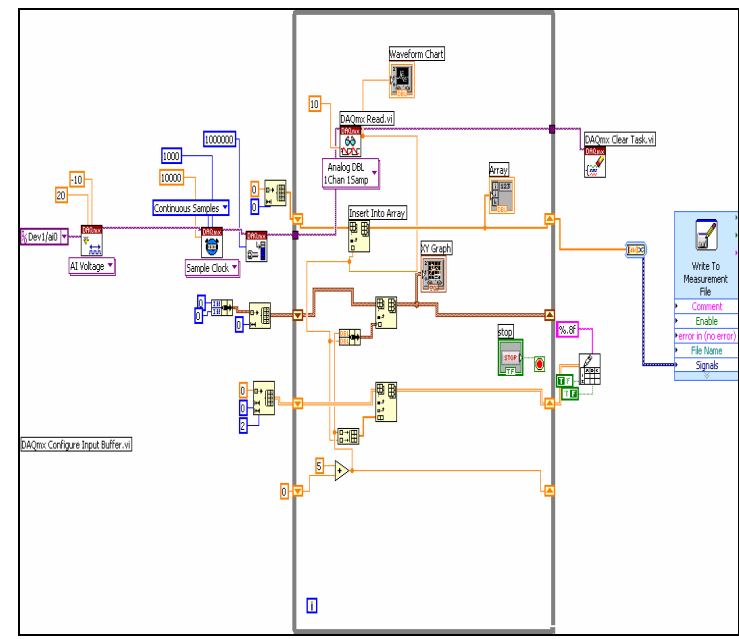

Figure 2. block diagram of the labVIEW program of Raman spectrophotometer.

The block diagram contains four sections:

1-Create physical channel 2-Set sample rate

3-Read and write 4-Clear. 


\section{RESULTS}

The results obtained after installation of the LabVIEW card are presented in figures and graphs shown below. These include Raman spectra of two standard sample solutions (i.e. Sodium sulfate and benzene).

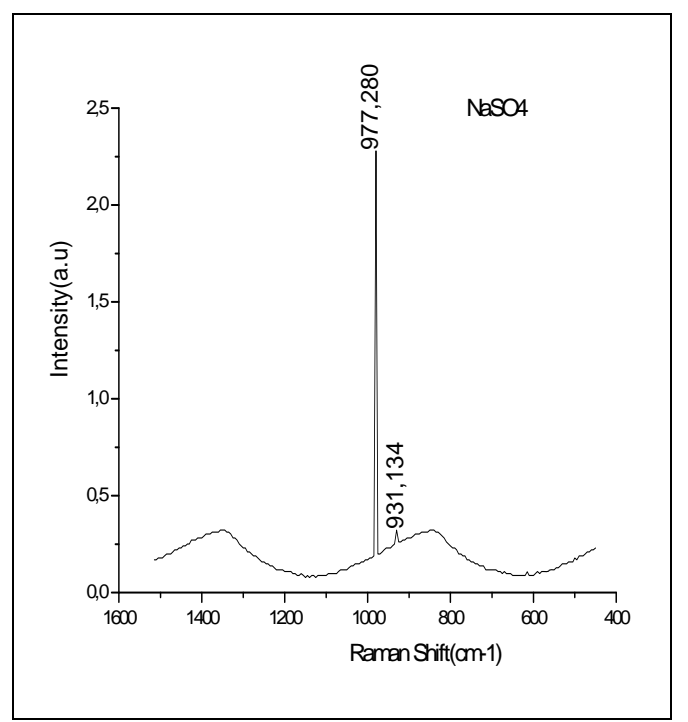

Figure 3. Raman shift of the $\mathrm{Na}_{2} \mathrm{SO}_{4}$

This sample was used as an example of the study of the applications of Raman spectroscopy in the study of inorganic solid materials, the spectra peak was found to be at $977.280 \mathrm{~cm}-$

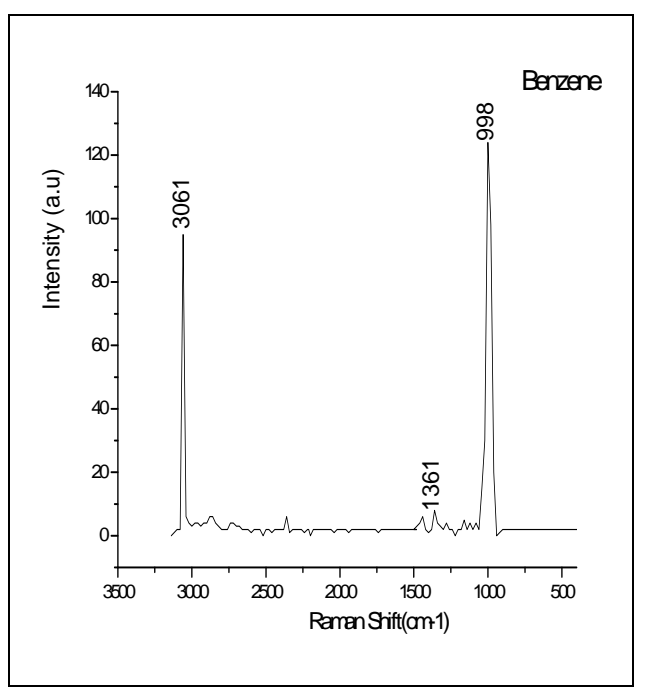

Figure 4. Raman shift of benzene
This sample was used as an example of aromatic components and the spectra peak was found to be at $998 \mathrm{~cm}$ 1.When compared with results from literature which was found to be at $999 \mathrm{~cm}-1$ [6] the difference is negligible.

\section{CONCLUSION}

The main purpose of this study was to develop and interface the old version Raman spectrophotometer instrument with a personal computer. This was done using different procedures of the hardware and software by designing a data acquisition system. An extensive set of measurements after interfacing were done. It is generally accepted that the measurement of the sample using LabVIEW card, is more accurate and it gives an additional properties which were not found in the normal chart recorder.

The interfaced instrument has been presented and operated successfully. This was done by matching the output results from different samples with the correspondent measured results from other instrument in the same company, which showed high consistency.

\section{REFERENCES}

[1] Fran Adam and M.Dellhaye,"Evaluation of instrumentation for detection of the Raman Effect", Waters Symposium ,Pittcon, 2003

[2] James .D and Staney K.Crouchi, ,"Spectrochemical Analysis ",1999

[3] Labview getting started guide, National Instrument Co., Texas, 2003.

[4] Labview Data Acquisition, National instrument Co., Texas, 2006.

[5] -Handbook of analytical instrument", 2nd edition, R.S Khandpour,Tata McGraw,New Delhi, Hill publishing company limited ,2006

[6] Walker and H.Straw ,"Spectroscopy", London ,Champing and Hill , 1988

[7] Skoog Douglas A., F. James Holler and Timothy.Nieman."Principles of InstrumentalAnalysis",. Philadelphia, Harcour, 1998.

\section{AUTHORS}

A.I. Adam is with Central laboratory ministry of sciences and technology Sudan, Khartoum, Sudan. Code: (11121), Tel. +249121506668, (alaghib@hotmail.com)

S. T. Kafi is assistance professor at School of Physics, Faculty of Sciences and Technology, Alneelian University, Code:(11121),P.O.Box :(12702),Tel.+249-183770058,Fax.+249-183-776338

Manuscript received 11 November 2009. Published as resubmitted by the authors 27 April 2010. 